\title{
COVID-19 pulmonary pathology: a multi-institutional autopsy cohort from Italy and New York City
}

\author{
Alain C. Borczuk ${ }^{1}$ - Steven P. Salvatore ${ }^{1}$ Surya V. Seshan ${ }^{1} \cdot$ Sanjay S. Patel $\mathbb{D}^{1} \cdot$ James B. Bussel $^{2} \cdot$ Maria Mostyka $^{1}$. \\ Sarah Elsoukkary ${ }^{1} \cdot$ Bing He $^{1} \cdot$ Claudia Del Vecchio $^{3}$. Francesco Fortarezza $\circledast^{4} \cdot$ Federica Pezzuto $^{4} \cdot$ Paolo Navalesi $^{5}$. \\ Andrea Crisanti ${ }^{3} \cdot$ Mary E. Fowkes $\mathbb{D}^{6} \cdot$ Clare H. Bryce $^{6} \cdot$ Fiorella Calabrese $^{4} \cdot$ Mary Beth Beasley $^{6}$
}

Received: 6 July 2020 / Revised: 10 August 2020 / Accepted: 10 August 2020 / Published online: 2 September 2020

(c) The Author(s), under exclusive licence to United States \& Canadian Academy of Pathology 2020

\begin{abstract}
SARS-CoV-2, the etiologic agent of COVID-19, is a global pandemic with substantial mortality dominated by acute respiratory distress syndrome. We systematically evaluated lungs of 68 autopsies from 3 institutions in heavily hit areas (2 USA, 1 Italy). Detailed evaluation of several compartments (airways, alveolar walls, airspaces, and vasculature) was performed to determine the range of histologic features. The cohort consisted of 47 males and 21 females with a median age of 73 years (range 30-96). Co-morbidities were present in most patients with $60 \%$ reporting at least three conditions. Tracheobronchitis was frequently present, independent from intubation or superimposed pneumonia. Diffuse alveolar damage (DAD) was seen in $87 \%$ of cases. Later phases of DAD were less frequent and correlated with longer duration of disease. Large vessel thrombi were seen in $42 \%$ of cases but platelet (CD61 positive) and/or fibrin microthrombi were present at least focally in $84 \%$. Ultrastructurally, small vessels showed basal membrane reduplication and significant endothelial swelling with cytoplasmic vacuolization. In a subset of cases, virus was detected using different tools (immunohistochemistry for SARS-CoV-2 viral spike protein, RNA in situ hybridization, lung viral culture, and electron microscopy). Virus was seen in airway epithelium and type 2 pneumocytes. IHC or in situ detection, as well as viable form (lung culture positive) was associated with the presence of hyaline membranes, usually within 2 weeks but up to 4 weeks after initial diagnosis. COVID-19 pneumonia is a heterogeneous disease (tracheobronchitis, DAD, and vascular injury), but with consistent features in three centers. The pulmonary vasculature, with capillary microthrombi and inflammation, as well as macrothrombi, is commonly involved. Viral infection in areas of ongoing active injury contributes to persistent and temporally heterogeneous lung damage.
\end{abstract}

These authors contributed equally: Alain C. Borczuk, Fiorella Calabrese, Mary Beth Beasley

Supplementary information The online version of this article (https:// doi.org/10.1038/s41379-020-00661-1) contains supplementary material, which is available to authorized users.

Alain C. Borczuk

alb9003@med.cornell.edu

1 Department of Pathology and Laboratory Medicine, New-York Presbyterian Hospital-Weill Cornell Medicine, New York, NY, USA

2 Department of Pediatrics, New-York Presbyterian Hospital-Weill Cornell Medicine, New York, NY, USA

\section{Introduction}

Severe acute respiratory distress syndrome-associated coronavirus-2 (SARS-CoV-2), the etiologic agent of coronavirus disease 2019 (COVID-19), was initially identified in the Hubei province of China in December 2019 [1] and declared a pandemic by the World Health Organization in March 2020 [2]. As of July 5, 2020, there have been nearly 11.5 million confirmed cases worldwide and over 500,000 deaths. In the USA, there have been over 2.8 million

3 Department of Molecular Medicine, Padua University Hospital, Padua, Italy

4 Department of Cardiac, Thoracic, Vascular Sciences and Public Health, Padua University Hospital, Padua, Italy

5 Department of Medicine, Padua University Hospital, Padua, Italy

6 Department of Pathology, Molecular and Cell-Based Medicine, Icahn School of Medicine at Mount Sinai, New York, NY, USA 
confirmed cases, with New York City alone reporting just over 216,000 confirmed cases and nearly 24,000 deaths. Italy has recorded over 240,000 cases and just under 35,000 deaths (https://coronavirus.jhu.edu/).

SARS-CoV-2 is a coronavirus which utilizes angiotensin converting enzyme 2 (ACE2) as a source of cellular entry, as do the coronavirus agents of SARS and Middle East respiratory syndrome (MERS). ACE2 is expressed in lung alveolar cells, bronchial epithelium and vascular endothelial cells explaining why the respiratory tract and lung serve as a primary point of viral entry [3-5]. Indeed, while COVID-19 has been shown to impact a variety of organ systems [6-9], respiratory system pathology predominates with mortality linked primarily to acute respiratory distress syndrome (ARDS) [3]. Patients experience marked abnormalities in the coagulation system, particularly elevated D-dimer levels, which predispose patients to thrombotic disease [10]. Proinflammatory cytokines such as interleukin-6 (IL-6) are also elevated, similar to that seen in sepsis-induced ARDS in general [11]. While COVID-19 patients experience ARDS, many retain high levels of respiratory compliance in spite of the presence of severe hypoxemia, which is atypical in classic ARDS [12]. Radiologic evaluation of COVID-19 cases has similarly shown findings generally described as being more akin to organizing pneumonia, particularly in the earlier phases of the disease [13, 14]. Such disparate clinical and radiographic findings compared to classic ARDS would suggest the pulmonary pathology of COVID-19-related ARDS has different histologic features than those typically seen in association with non-COVID-19 ARDS.

Autopsy reports of the lungs in COVID-19 to date have primarily shown diffuse alveolar damage (DAD) or acute lung injury. The pulmonary autopsy findings are primarily limited to case reports or single center cohort studies, with one exception [15-26]. More recent findings have reported a wider spectrum of histological lesions involving both the epithelial and vascular components in lung and other organs. This has led to an increased awareness of the intrinsic complexity of the disease.

The aim of this study is to systematically evaluate a large number of lung autopsy specimens from multiple institutions (two in New York City covering the boroughs of Manhattan, Queens, and Brooklyn and one from North Italy covering a part of the Veneto region) to provide insight into the pathological underpinnings of the disease.

\section{Material and methods}

\section{Study population}

This is a multicenter retrospective study of 68 consecutive COVID-19 autopsies performed in 3 centers (New York
Presbyterian-Weill Cornell Medicine-WCMC, NYC, USA $(n=23)$, Mount Sinai Hospital-MSH, NYC, USA $(n=$ $25)$ and University Hospital of Padova-UHP, IT $(n=20))$ - and conducted in accordance with the principles of the Declaration of Helsinki and approved by local Medical Ethical Committee of the three referral centers. Written informed consent for autopsy study was obtained from next of kin and this was the sole selection criterion. According to the New Coronavirus Pneumonia Prevention and Control Program (7th edition), the diagnosis of COVID-19 was confirmed by nucleic acid testing of nasopharyngeal swabbed secretion, radiologic features of viral pneumonia, and clinical symptoms. Relevant laboratory values were recorded; however, several patients died prior to laboratory testing.

\section{Lung tissue sampling, processing, and analysis}

Lung tissue was obtained from autopsies with a postmortem interval ranging from 1 to 16 days during March 19 to April 25, 2020 (see Supplemental material). A median of 19 (from 8 to 30) lung tissue blocks including subpleural and central parts, were sampled, along with transverse tracheal and bronchus sections. Full thoracic and abdominal autopsies were performed in 63 cases, chest only in 3 cases, and 2 were lung tissue only. In 66 cases, all lung lobes were samples, including central and peripheral areas. In two cases, large postmortem lung wedge samples were taken from all lobes on the right, but tracheal sections were not taken and entire lungs could not be weighed. In one case, dense adhesions precluded accurate lung weights, but all lobes were sampled. Tissue specimens were fixed in $10 \%$ formalin, or Karnowsky for electron microscopy (EM), for 48-72 h. Hematoxylin and eosin stain was performed, and special stains to highlight microorganisms (e.g., Gram, Warthin Starry, and Grocott stain) were carried out in all WCMC cases, and in selected cases at other sites. EM was performed in 14 lung and tracheal tissues using a transmission electron microscope (TEM, HT-7800, Japan). Immunohistochemistry was carried out on selected cases to characterize the platelet component of microthrombi (CD61 clone 2F2, Leica Biosystems, IL) and to identify SARS$\mathrm{CoV}-2$ viral spike protein (Genetex clone $1 \mathrm{~A} 9$ at 1:75 dilution with 20-min antigen retrieval at $\mathrm{pH} 9.0$ on Leica Bond III automated instrument). SARS-CoV-2 RNA was detected in trachea and lung by RNAscope technology (Advanced Cell Diagnostics, Newark, CA), using SARSCoV-2 2019-S (cat. 848561), for detection of viral spike protein-encoding RNA. RNA integrity was assessed using a probe targeting the $U B C$ (Ubiquitin C) housekeeping gene. Overall, 23 cases were examined for spike protein IHC, and all positives were confirmed using RNA in situ for spike protein-encoding RNA. In addition, five cases of 
non-SARS-CoV-2 with ARDS were included as negative controls for both immunohistochemistry and in situ hybridization.

Postmortem lung tissues from six cases were available for viral isolation. Briefly, virus isolation was performed using African green monkey kidney (Vero) cells. When a diffuse, refractile, rounding, cytopathic effect was noted, the Vero cell culture supernatant was passaged to a fresh Vero cell culture tube to ensure reproducibility of the cytopathic effect. SARS-CoV-2 in the supernatant was further confirmed by reverse transcription polymerase chain reaction using primers described previously [27].

Histological evaluation was performed by two pathologists from WCMC and UHP on each case, and one from MSH (WCMC - ACB, SPS, UHP-FC, FP, MSH-MBB) and selected specimens were scanned by whole-slide image technique using an Aperio slide scanner with resolution of $0.24 \mu \mathrm{m} /$ pixel. Image files of six cases total from UHP and WCMC were uploaded on a Leica hosted web-based site after de-identification to establish concordance of the grading system using shared scoring sheets and iterative discussions. To establish the criteria, FC and FP scored all cases blindly with a kappa of 0.6-1 (Cohen kappa) for the various criteria.

Histologic features were evaluated for presence and graded on extent: absent: 0 ; focal $\leq 50 \%$ and diffuse: $>50 \%$ of examined lung tissue. The presence of other concomitant lung lesions was also recorded (see Supplemental material). For microthrombi, small arteries were defined as $<1.0 \mathrm{~mm}$; the term "mid-sized pulmonary vessels" was used for those larger than $1.0 \mathrm{~mm}$, often grossly visible, but not pulmonary emboli of main pulmonary artery.

\section{Statistical analysis}

Data that were normally distributed are presented as mean (SD); data not having a normal distribution are presented as medians (ranges). Categorical variables are summarized as counts and percentages. All data were analyzed with Statistica, version 13 (StatSoft).

\section{Results}

\section{Clinical data}

Clinical characteristic and laboratory results of patients are summarized in Table 1 and listed by case in Supplemental material. The 68 COVID-19 patients included 47 males $(69 \%)$ and $21(31 \%)$ females with a median age of 73 years (overall range 30-96 years; interquartile range, 60-82 years). Smoking status was known in $82 \%$ of cases; only 3
Table 1 Main clinical data of the study population.

\begin{tabular}{|c|c|c|c|}
\hline \multicolumn{2}{|l|}{ Parameters } & \multicolumn{2}{|l|}{ Parameters } \\
\hline $\begin{array}{l}\text { Age (year), } \\
\text { median (Q1-Q3) }\end{array}$ & $73(60-82)$ & $\begin{array}{l}\text { Co-morbidity, } \\
n(\%)\end{array}$ & \\
\hline Gender, $n(\%)$ & & Absent & $2(3 \%)$ \\
\hline Males & $47(69 \%)$ & 1 & $8(12 \%)$ \\
\hline \multirow[t]{3}{*}{ Females } & $21(31 \%)$ & 2 & $15(22 \%)$ \\
\hline & & $\geq 3$ & $41(60 \%)$ \\
\hline & & NA & $2(3 \%)$ \\
\hline Race, $n(\%)$ & & Treatment, $n(\%)$ & \\
\hline White & $38(56 \%)$ & Anticoagulant & $18(26 \%)$ \\
\hline Hispanic & $17(25 \%)$ & Antiviral & $1(2 \%)$ \\
\hline Black & $7(10 \%)$ & Immunomodulant & $7(10 \%)$ \\
\hline Asian & $2(3 \%)$ & $\begin{array}{l}\text { Anticoagulant }+ \\
\text { antiviral }\end{array}$ & $6(9 \%)$ \\
\hline \multirow[t]{2}{*}{ Other } & $4(6 \%)$ & $\begin{array}{l}\text { Anticoagulant }+ \\
\text { immunomodulant }\end{array}$ & $25(37 \%)$ \\
\hline & & Only supportive & $11(16 \%)$ \\
\hline \multicolumn{4}{|l|}{ Smoke, $n(\%)$} \\
\hline Yes & $3(4 \%)$ & $\begin{array}{l}\text { Days intubated, } \\
\text { median (Q1-Q3) }\end{array}$ & $0(0-5)$ \\
\hline Former & $18(26 \%)$ & & \\
\hline No & $35(52 \%)$ & & \\
\hline \multirow[t]{2}{*}{ NA } & $12(18 \%)$ & & \\
\hline & & $\begin{array}{l}\text { Days of disease, } \\
\text { median }(\mathrm{Q} 1-\mathrm{Q} 3)\end{array}$ & $11(8-19)$ \\
\hline \multicolumn{4}{|l|}{ Fever $\left({ }^{\circ} \mathrm{C}\right)$} \\
\hline$\leq 37.5$ & $17(25 \%)$ & & $7.5(4.825-11.45)$ \\
\hline $37.6-38.5$ & $16(24 \%)$ & $\begin{array}{l}\text { WBC }\left(10^{9} / \mathrm{L}\right) \\
\text { median }(\mathrm{Q} 1-\mathrm{Q} 3)\end{array}$ & \\
\hline$>38.6$ & $28(41 \%)$ & & $0.77(0.5-1)$ \\
\hline \multirow[t]{2}{*}{ NA } & $7(10 \%)$ & $\begin{array}{l}\text { ALC }\left(10^{9} / \mathrm{L}\right) \\
\text { median }(\mathrm{Q} 1-\mathrm{Q} 3)\end{array}$ & \\
\hline & & $\begin{array}{l}\text { PLT }\left(10^{9} / \mathrm{L}\right) \\
\text { median }(\mathrm{Q} 1-\mathrm{Q} 3)\end{array}$ & $172(11.5-237.5)$ \\
\hline \multicolumn{4}{|l|}{ Cough, $n(\%)$} \\
\hline Yes & $32(47 \%)$ & $\begin{array}{l}\mathrm{DD}\left(10^{9} / \mathrm{L}\right) \\
\text { median }(\mathrm{Q} 1-\mathrm{Q} 3)\end{array}$ & $2447(1110.75-6885.3)$ \\
\hline No & $32(47 \%)$ & & \\
\hline \multirow[t]{2}{*}{ NA } & $4(6 \%)$ & & \\
\hline & & $\begin{array}{l}\mathrm{CRP}(\mathrm{mg} / \mathrm{L}) \\
\text { median }(\mathrm{Q} 1-\mathrm{Q})\end{array}$ & $55.2(24.4-206.2)$ \\
\hline \multicolumn{4}{|c|}{ Shortness of breath, $n(\%)$} \\
\hline Yes & $54(80 \%)$ & $\begin{array}{l}\text { ESR }(\mathrm{mm} / \mathrm{h}) \\
\text { median }(\mathrm{Q} 1-\mathrm{Q} 3)\end{array}$ & $68(36-104)$ \\
\hline No & $11(16 \%)$ & & \\
\hline NA & $3(4 \%)$ & $\begin{array}{l}\text { IL-6 }(\mathrm{ng} / \mathrm{L}) \\
\text { median (Q1-Q3) }\end{array}$ & $122.5(45-231.5)$ \\
\hline
\end{tabular}

$N A$ not available, $W B C$ white blood cells, $A L C$ absolute lymphocytes count, $P L T$ platelets, $D D$ D-dimer, $C R P$ C-reactive protein, $E S R$ erythrocyte sedimentation rate, $I L-6$ interleukin-6.

patients (5\%) were active smokers and 18 (32\%) former smokers.

All patients had the positive results for SARS-CoV-2 by PCR by nasopharyngeal swab. Information regarding comorbidities was available for 65 patients. At least one comorbidity was present in all but three patients, with the most common being hypertension $(65 \% ; 42 / 65)$ and diabetes or 
prediabetes $(45 \% ; 29 / 65)$. Twenty-one of the 65 patients had 1 or more types of cardiac disease, 12 had obesity, 9 had chronic kidney disease, 7 had hyperlipidemia, 7 had dementia, 6 had asthma, 6 had chronic obstructive pulmonary disease (COPD), 4 had undergone either kidney or liver transplant, 2 had HIV, and 2 had hepatitis. Nine patients $(13 \%)$ had a history of current or prior malignancy. In more than half of patients $(60 \%)$, at least three preexisting co-morbidities such as diabetes, hypertension, chronic ischemic heart disease, chronic kidney disease, COPD, and/or dementia were reported to be present at the same time. The most common symptoms at onset were shortness of breath (80\%), fever (65\%), and cough (47\%). Premortem laboratory results showed elevated levels of D-dimer in $92 \%$ patients with testing (not available in 17 patients), mild thrombocytopenia in $31 \%$ (not available in 9), and lymphopenia in $79 \%$ (not available in 11). IL-6 level was increased in 31 of 33 patients measured (94\%) and CRP elevated in 49 of 50 patients (98\%) in which it was measured, with level $>10$ in $90 \%$.

While the majority presented with, or developed respiratory failure during hospitalization, only 27 (40\%) were intubated with mechanical ventilation. Reasons for this were varied but included do not intubate orders and the rapidity of disease progression. The presence of an associated or superimposed nonviral (bacterial or fungal) pneumonia by antemortem or postmortem culture with consistent histological examination, or by special stains for microorganisms was seen in 18 patients $(26.5 \%)$.

\section{Pathological findings}

Macroscopic examination showed congested and edematous lungs with patchy involvement as well as area of diffuse consolidation. This was evidenced by combined weight of $>1300 \mathrm{~g}$ (normal average $840 \mathrm{~g}$; upper limit of normal 1300) [28] in $92 \%$ of evaluable cases. Gross patterns of parenchymal involvement included primarily diffuse consolidation as well as patchy areas of firm discoloration (Fig. 1a, b).

In the majority of cases upper airways (trachea and large bronchi) were widely patent without mucus plugs. Focal white patches were seen (Fig. 2a, b), which histologically showed mucosal ulceration with mixed inflammatory cell infiltration including neutrophils and fibrin (Fig. 2c, d). Large airway inflammation was seen in 92\% (35/38) patients who were never intubated, including acute inflammation in $45 \%(17 / 38)$ and chronic inflammation in $47 \%$ (18/38). No significant association was seen with large airway inflammation overall, acute inflammation, or chronic inflammation and intubation, by Fisher's exact test. Also, large airway inflammation was seen in 94\% (45/48) of patients with no associated bacterial or fungal pneumonia, including acute large airway inflammation in 52\%. No significant relationship was seen between large airway inflammation (overall, acute, and chronic) and acute bacterial or fungal pneumonia, by Fisher's exact test.

Microscopic evaluation of lungs was scored in different anatomic areas (airways, alveoli, and vascular bed) for
Fig. 1 Gross pathology, lung parenchyma. a This right lung alone weighed $1100 \mathrm{~g}$ and showed diffuse consolidation. b A pattern of patchy areas of gray-white consolidation was also frequently seen.

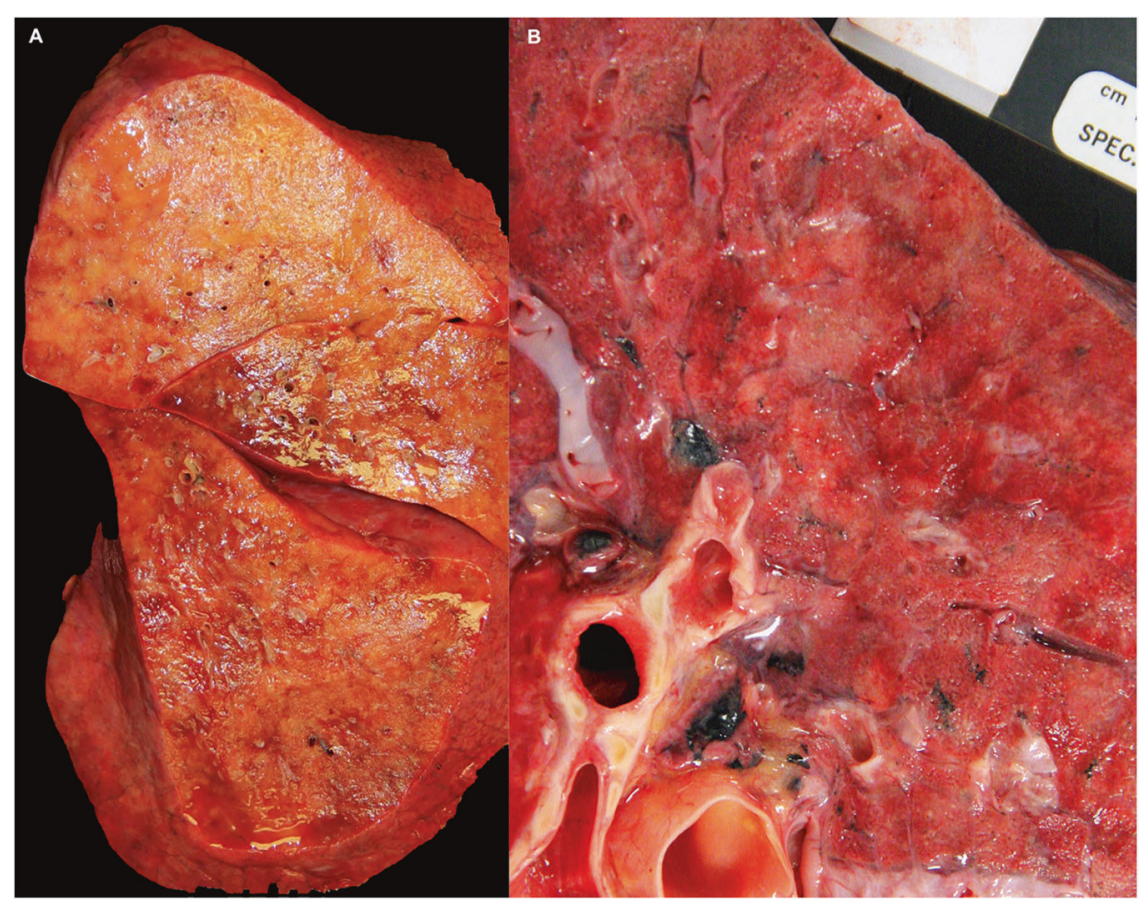


Fig. 2 Tracheobronchial inflammation in COVID-19. $\mathbf{a}, \mathbf{b}$ are gross photographs of trachea and main stem bronchus showing circumscribed white patches of $2.0-3.0 \mathrm{~mm}$ in diameter. c Microscopy of these lesions show ulceration with acute and chronic inflammation, $\mathbf{d}$ some with associated necrosis and fibrin. (a, b Gross photograph, Hematoxylin and eosin stain, $\mathbf{c} \times 50$ and $\mathbf{d} \times 100$ ).

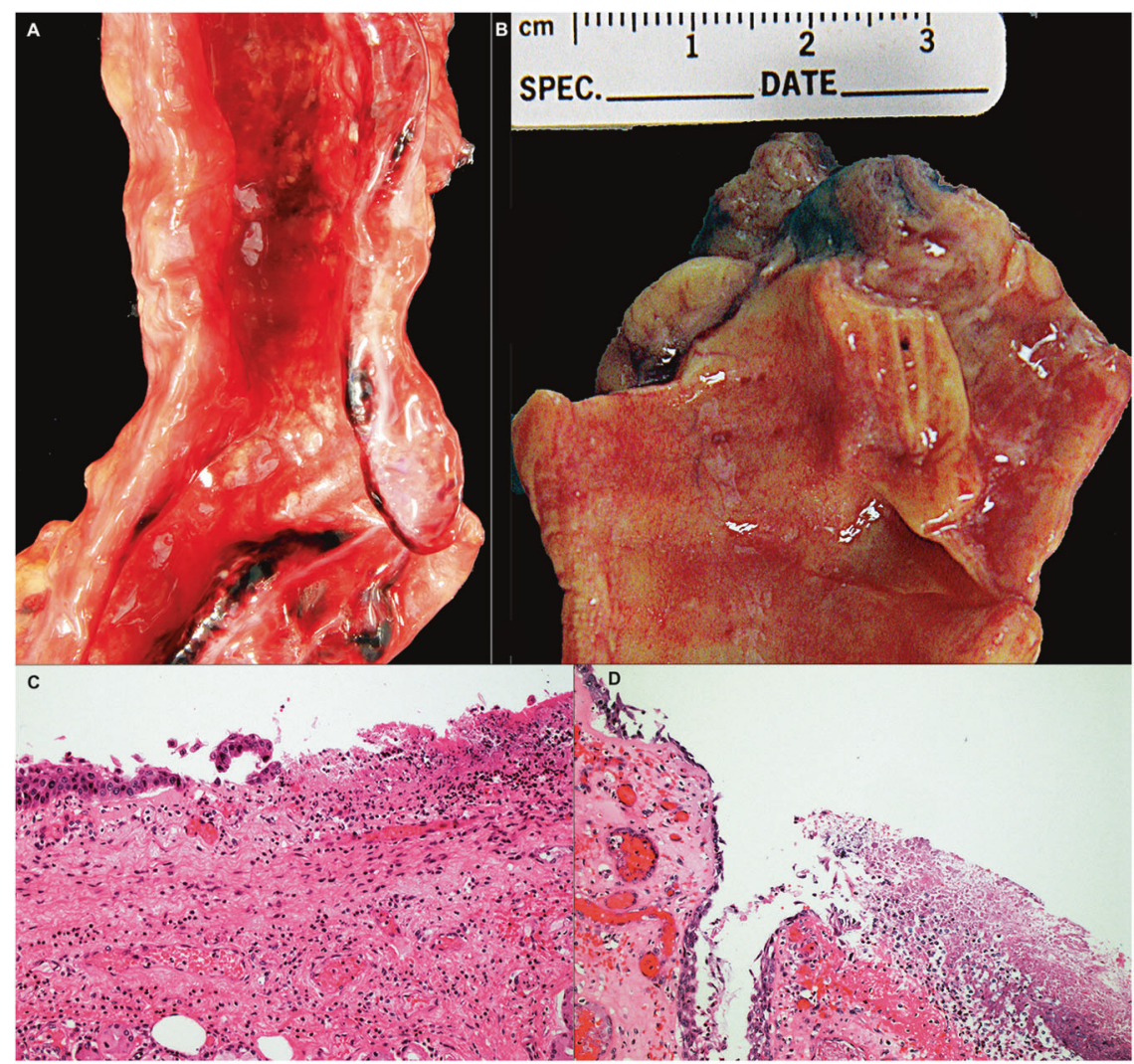

patterns of injury showing frequent presence of airways inflammation and alveolar zones with hyaline membranes and type 2 pneumocyte (AT2 cell) hyperplasia. Less frequently encountered, were interstitial fibroblastic proliferation with fibromyxoid stroma, organizing pneumonia, squamous metaplasia, and alveolar wall acute inflammation (Table 2). AT2 cell hyperplasia and interstitial fibroblastic proliferation was more likely to be identified with longer duration of illness (Fig. 3). However, diffuse hyaline membranes were seen in patients with both short and longer duration of disease, with an average day of illness of just under 15 days (Fig. 3). Of the nine patients without hyaline membranes, five had acute inflammation of alveolar walls, three had saddle or main pulmonary artery emboli, and one had cardiac disease and little pulmonary involvement.

Typical features of DAD with hyaline membranes (Fig. 4a) and AT2 cell hyperplasia (Fig. 4b) were present, at least focally, in $87 \%$ of patients. Pneumocytes frequently appeared atypical, enlarged, and sometimes multinucleated with syncytial features (Fig. 4c) as well as basophilic intracytoplasmic inclusions (Fig. 4d). However, these were not confirmed by immunohistochemistry, in situ hybridization or EM to be viral inclusions. Nuclear inclusions were not seen. Organizing pneumonia (34\%) and squamous metaplasia (43\%) were seen in those autopsies with a longer disease duration (Figs. 5a, b and 3), with a range of
5-34 days and 5-32 days, respectively. For organizing pneumonia, diffuse disease was seen in only two cases with under 10 days of disease. An alveolar wall injury with neutrophils or lymphocytes with capillary proliferation and necrosis was seen in a subset of cases, as shown in Fig. 5c, suggesting an endotheliitis.

Large vessel thrombi were seen, focally or diffusely, in $42 \%$ of autopsied lungs (Fig. 6a). These were seen in patients with longer average disease duration (Fig. 3). In addition, microthrombi, distinct from grossly visible large thrombi, containing fibrin and platelets were frequently detected in small arteries $(<1.0 \mathrm{~mm})$ and in alveolar capillaries, in some instances mixed with inflammatory cells (Fig. 6b, c). Of the 44 patients with diffuse microthrombi, 17 (39\%) has larger vessel thrombi. Of the 22 patients with diffuse large vessel thrombi, 17 (77\%) also had microthrombi. Some thrombi were rich in platelets, seen as granular intravascular material and highlighted by CD61 immunohistochemistry (Fig. 6d). These microthrombi were consistently detected, at least focally and often diffusely, in $84 \%$ of lungs. The diffuse finding of microthrombi was seen with shorter average disease duration as compared to larger vessel thrombi. Interestingly, while anticoagulation therapy was reported in $71 \%(48 / 68)$ of patients, $46 \%(22 / 48)$ of anticoagulated patients had large thrombi, and $88 \%(42 / 48)$ had microthrombi of arterioles and capillaries. No significant 
Table 2 Main pathological data of the study population.

\begin{tabular}{|c|c|c|c|}
\hline Parameters & $\begin{array}{l}\text { Total } \\
(N=68)\end{array}$ & Parameters & $\begin{array}{l}\text { Total } \\
(N=68)\end{array}$ \\
\hline \multicolumn{2}{|l|}{ Airways } & \multicolumn{2}{|l|}{ Other lesions } \\
\hline Tracheobronchial inflammation, $n(\%)$ & & \multicolumn{2}{|c|}{ Number of other pathological lesions detected, $n(\%)$} \\
\hline Acute, diffuse & $24(35 \%)$ & Absent & $27(40 \%)$ \\
\hline Acute, focal & $8(12 \%)$ & 1 & $31(45 \%)$ \\
\hline Chronic, diffuse & $28(41 \%)$ & 2 & $8(12 \%)$ \\
\hline Chronic, focal & 0 & $\geq 3$ & $2(3 \%)$ \\
\hline Absent & $4(6 \%)$ & & \\
\hline Not available & $4(6 \%)$ & & \\
\hline \multicolumn{2}{|l|}{ Alveolar space } & \multicolumn{2}{|l|}{ Alveolar wall } \\
\hline \multicolumn{2}{|l|}{ Acute inflammation, $n(\%)$} & \multicolumn{2}{|c|}{ Acute inflammation, $n(\%)$} \\
\hline Present, diffuse & $18(27 \%)$ & Present, diffuse & $29(43 \%)$ \\
\hline Present, focal & $11(16 \%)$ & Present, focal & $5(7 \%)$ \\
\hline Absent & $39(57 \%)$ & Absent & $34(50 \%)$ \\
\hline \multicolumn{2}{|l|}{ Chronic inflammation, $n(\%)$} & \multicolumn{2}{|c|}{ Chronic inflammation, $n(\%)$} \\
\hline Present, diffuse & $55(81 \%)$ & Present, diffuse & $59(87 \%)$ \\
\hline Present, focal & $8(12 \%)$ & Present, focal & $6(9 \%)$ \\
\hline Absent & $5(7 \%)$ & Absent & $3(4 \%)$ \\
\hline \multicolumn{2}{|l|}{ Hyaline membranes, $n(\%)$} & \multicolumn{2}{|c|}{ Pneumocyte type II hyperplasia with interstitial fibroblasts, $n(\%)$} \\
\hline Present, diffuse & $42(61.8 \%)$ & Present, diffuse & $17(25 \%)$ \\
\hline Present, focal & $17(25 \%)$ & Present, focal & $7(10 \%)$ \\
\hline Absent & $9(13.2 \%)$ & Absent & $44(65 \%)$ \\
\hline \multicolumn{4}{|l|}{ Pneumocyte type II hyperplasia, $n(\%)$} \\
\hline Present, diffuse & $37(54.4 \%)$ & \multicolumn{2}{|l|}{ Vessels } \\
\hline Present, focal & $9(13.2 \%)$ & Microthrombi, $n(\%)$ & $44(65 \%)$ \\
\hline \multirow[t]{3}{*}{ Absent } & $22(32.4 \%)$ & Present, diffuse & $13(19 \%)$ \\
\hline & & Present, focal & $11(16 \%)$ \\
\hline & & \multicolumn{2}{|l|}{ Absent } \\
\hline \multicolumn{4}{|l|}{ Organizing Pneumonia, $n(\%)$} \\
\hline Present, diffuse & $11(16 \%)$ & Large thrombi, $n(\%)$ & $22(32 \%)$ \\
\hline Present, focal & $12(18 \%)$ & Present, diffuse & $7(10 \%)$ \\
\hline \multirow[t]{2}{*}{ Absent } & $45(66 \%)$ & Present, focal & $39(58 \%)$ \\
\hline & & Absent & \\
\hline
\end{tabular}

association was seen between anticoagulation therapy and the presence of large thrombi or microthrombi, by Fisher's exact test.

The presence of vascular injury without prominent DAD histology was observed in 11 patients, including increased alveolar neutrophils or endothelial reaction with or without fibrin. This was not associated with extrapulmonary vasculitis, and the clinical presentation included fever, cough, and shortness of breath. In one case this was associated with rapid progression within $24 \mathrm{~h}$; however, this was not a consistent finding. Immunohistochemistry and in situ hybridization was performed in 2 of 11 of these cases, and endothelial reactivity was not observed. Ultrastructural analysis of small blood vessels showed several alterations in one case: swelling of the cytoplasm with vacuolization and reduplication of basement membrane (Fig. 6e, f). At higher magnification, putative viral particles were detected in endothelial cell cytoplasm (Fig. 6e, inset).

Other histological lesions, including infections (mainly bacterial, rarely fungi and mycobacterial), tumors (three malignant and one benign), aspiration pneumonia (two cases), and lung infarcts (eight cases) were detected in $60 \%$ of cases.

Ancillary studies were performed to confirm the presence of virus in different cell types. Immunohistochemistry for viral spike protein and RNA in situ hybridization for viral spike RNA showed reactivity in tracheal epithelium 
Fig. 3 Scoring of lung pathology, by days of disease. The frequency of lung findings scored as absent, focal, or diffuse by percent of total patients evaluated for that feature is shown on the left axis (bar graph) while the average days of illness for that feature (absent, focal, or diffuse) is shown on right axis (line graph).
Fig. 4 Patterns of acute respiratory distress syndrome. a A combination of hyaline membranes, type 2 cell hyperplasia, and interstitial fibroblastic proliferation is shown. b Type 2 pneumocyte hyperplasia without fibroblastic proliferation. c Pneumocytes were enlarged and atypical, with (d) some pneumocytes showing multinucleated syncytial features and/or basophilic intracytoplasmic inclusions (Hematoxylin and eosin stain, a, b, $\mathbf{c} \times 100$, d $\times 150$ ).
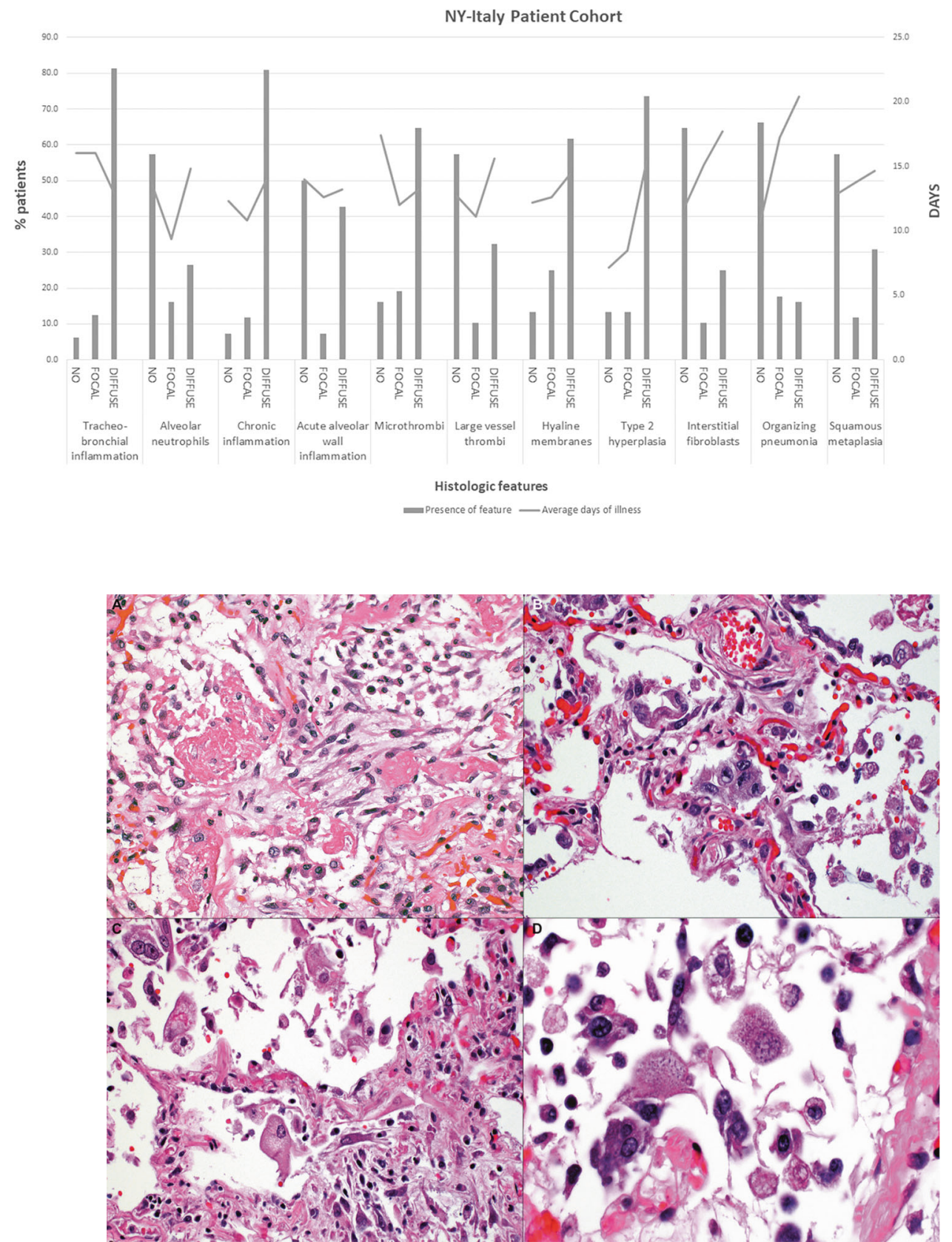

(Fig. 7a, b) and in areas of hyaline membranes as well as atypical alveolar AT2 cells (Fig. 7c-e). Ultrastructural examination confirmed the presence of coronavirus in an AT2 cell (Fig. 7f).

Correlation of immunohistochemistry and RNA in situ findings and duration of disease was performed in 23 cases (Fig. 8). Interestingly, the majority of autopsy lungs in the first 2 weeks of disease had evidence of viral infection in the lung, seen in hyaline membranes and adjacent cells. These foci were often patchy. Less frequently, IHC and in situ positive cases were seen beyond 2 weeks. The evaluation of viral lung culture in six patients showed viable SARS-CoV-2 in all cases, mainly within the first 2 weeks, with one exception, after 26 days from clinical presentation.

\section{Discussion}

We report a detailed examination of lung pathology in a series of 68 cases of COVID-19 positive patients, autopsied in three institutions, two in New York City and one in Italy, regions severely affected by the COVID-19 pandemic. The clinical and histologic findings were similar among the three institutions despite differing patient populations between the Italian and US cohorts. Our clinical findings are 


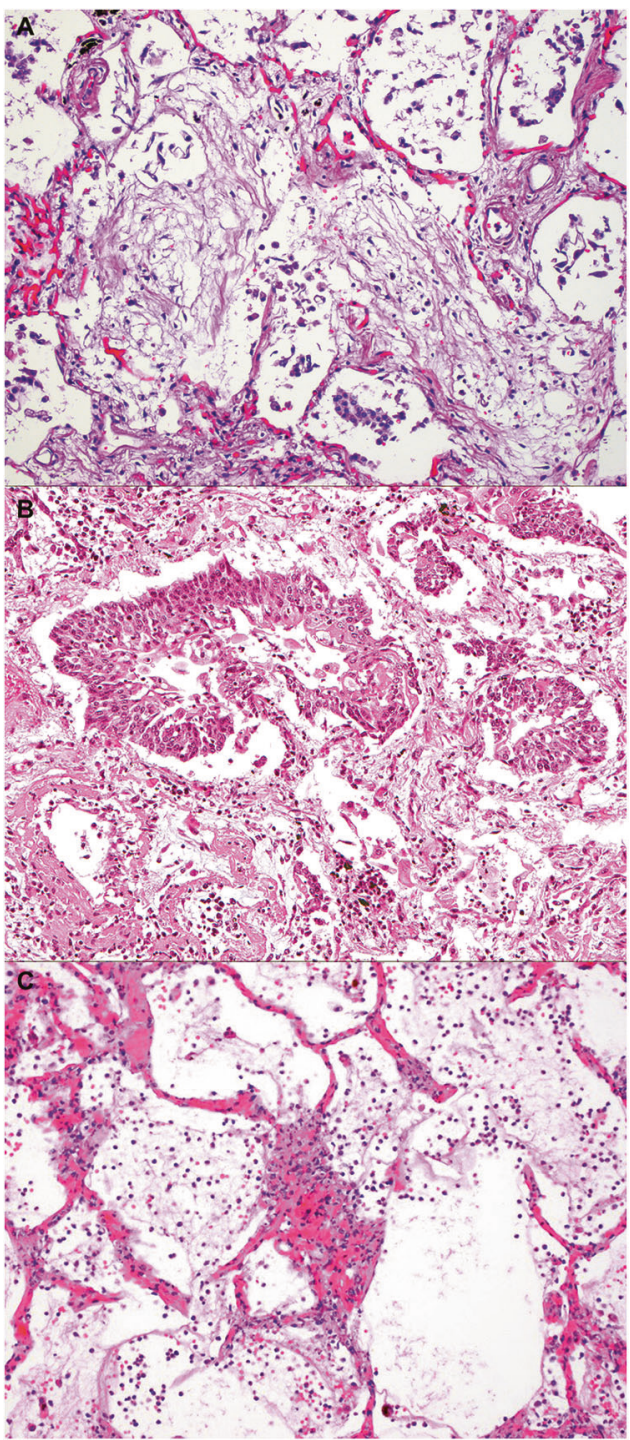

Fig. 5 Less commonly encountered histologic features. a Young collagen with features of organizing pneumonia. b Squamous metaplasia in alveolar space. c Alveolar wall injury with neutrophils, and endothelial injury was seen in a subset of early disease duration cases (Hematoxylin and eosin stain, $\mathbf{a}, \mathbf{b}, \mathbf{c} \times 100$ ).

consistent with those seen in the current literature-that is older males with a high rate of co-morbid conditions [29]. Interestingly, we report a relatively low rate of current smokers, as well as a large proportion of never smokers, a finding consistent with previous reports [29, 30]. In contrast, other studies report ongoing smoking and COPD associated with progression and poor outcome in COVID19 [31] explained by upregulation of ACE2 in lower airway $[32,33]$. This leaves the role of smoking in COVID-19 severity inconclusive requiring larger series for confirmation; but smoking may be an important co-morbidity along with, for example, diabetes and hypertension, to create the same severity and possibly a cumulative effect of comorbidities on COVID-19 outcome.
This novel virus was identified as a cause for pneumonia in China [1]. Much of the recognition of this pneumonia has been radiologic, described as ground glass nodules with progression to consolidation [34]. Descriptions include and unilateral or bilateral lower lobe location with progression from unilateral to bilateral disease, with greater morbidity when consolidation and air bronchograms are present. This pattern of illness has been reported to evolve over $1-3$ weeks $[15,35,36]$. Thus, radiologists already identify certain features as classical for COVID-19. The pathology of this progression remains complex, but we have shown the frequent presence of tracheobronchial inflammation, histologic features of DAD at different stages, chronic interstitial inflammation, and vascular injury. Small and large vessel thrombi are seen with a subset of cases showing foci of acute capillary injury with neutrophils and necrosis. These findings suggest upper airway to alveolar progression, alongside unique vascular, and thrombosis-induced injury.

\section{COVID-19 as a disease of tracheobronchial and AT2 epithelial injury}

Severe forms of tracheobronchitis were consistently present in $88 \%$ of our cases. The SARS-CoV-2 inflammation of the trachea and bronchus was very frequent and appeared to coincide with small white aphthous ulcers grossly, which were often $2-3 \mathrm{~mm}$ in diameter, and sometimes relatively focal. Although some of these lesions could represent an iatrogenic effect of ventilation and superimposed bacterial infection, no association with intubation or bacterial pneumonia was seen. Thus, they more likely represent an intrinsic feature of the disease. Large airway findings have also been found by lung scintigraphy in a COVID-19 nonsmoker patient, with intense uptake on the proximal bronchi [37]. While in SARS and MERS this aspect was not emphasized, in H1N1 acute inflammatory cells and tracheobronchitis were a reported feature [38]. It was confirmed that tracheal epithelium and pneumocytes were virally infected [39]. Of note, other published series of biopsy only autopsies, or without special attention to tracheal and large bronchial sampling would not detect this alteration.

Mirroring the published radiological findings, pulmonary pathology was progressive in our autopsies, based on clinical course and histologic findings including subacute changes such as squamous metaplasia and fibroblastic proliferation alongside more acute changes such as hyaline membranes. Macroscopic nodularity represented patches of acute lung injury rather than organizing pneumonia. However, the histology speaks to a progressive disease that begins in the airway and extends to alveolar zones. This is evidenced by resolving organizing pneumonia, 
Fig. 6 Vascular injury in COVID-19 lung. a A gross image showing multiple thrombi. b In addition to large thrombi, smaller caliber arteries showing fibrin thrombi. c Thrombi were seen in small arteries, including precapillary channels). $\mathbf{d}$ In some cases, thrombi were predominantly composed of platelets, and were also seen in the capillary bed. e The endothelial basement membrane was diffusely reduplicated. At higher magnification some putative viral particles were evident in endothelial cell cytoplasm.

f Endothelial cells were swollen and showed numerous instances of cytoplasmic vacuolization. EC endothelial cell; EBM endothelial basement membrane; Ly lymphocyte; RC red cell (a-gross photograph, Hematoxylin and eosin $\mathbf{b}, \mathbf{c}, \times 100$, CD61 diaminobenzidine immunohistochemistry, $\times 100$, e-f transmission electron microscopy e $\times 12,000$, inset $\times 70,000, \mathbf{f} \times 6000$ ).

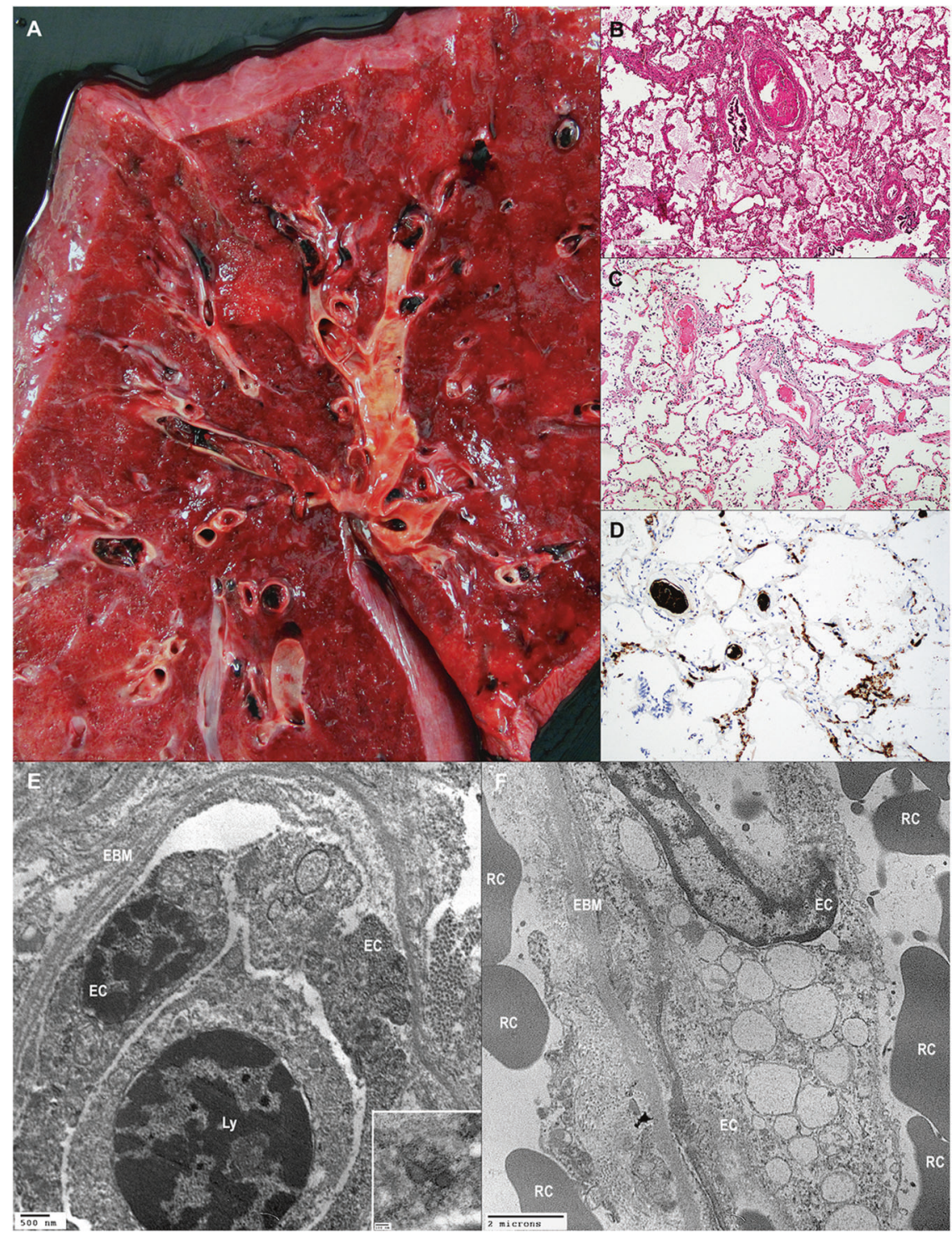

interstitial fibroblasts, and squamous metaplasia alongside acute DAD; therefore, some of this subacute injury likely precedes overt clinical symptoms - or at a minimum the severe respiratory ones. The cause of acceleration of respiratory disease remains uncertain but the finding of virus in AT2 cells and hyaline membranes amidst acute and organizing disease supports ongoing viral induced AT2 injury. Recent studies of 7 and 8 patients support the view that early disease is related to virus $[40,41]$; however, our immunohistochemistry and in situ hybridization findings in 23 patients, by week of disease, suggest new hyaline membrane associated injury is often related to virus within 2 weeks, and in some instances up to 4 weeks. This was also suggested by culture data. This may in part explain the juxtaposition of subacute changes (type 2 hyperplasia, fibroblasts, organizing pneumonia, and squamous metaplasia) with new injury. In fact, the foci of lung injury that are positive for virus are quite patchy and variable within the sampled lung and may account for the temporal heterogeneity of the DAD.

The involvement of the respiratory tract epithelium is not unexpected, since we have now a better understanding of the host cellular features needed for viral entry. The combination of ACE2 and transmembrane protease serine 2 (TMPRSS2) allows for viral entry into cells of the nasopharynx and large upper airway, as well in the alveolar AT2 cells [42]. This distribution fits well with the patterns of lung injury both in the upper airway and in the distal alveolar lung tissue. In our case series, the presence of the virus was characterized by EM, immunohistochemistry, and RNA in situ hybridization, in distal type 2 cell epithelium was predicted by the ACE2/TMPRSS2 cellular distribution, speaks to viral infection as one cause of ongoing alveolar injury. 
Fig. 7 Ancillary studies for tissue-based viral detection. a Immunohistochemistry for viral spike protein in tracheal epithelium. b RNAish for viral spike protein RNA, in same case as in (a). c Immunohistochemistry for viral spike protein in hyaline membranes and adjacent cells with (d) RNAish for viral spike protein RNA in the same area of a serial section as (c). e Lung tissue with area of new injury with background organization showing RNAish for viral spike protein in probable AT2 cells. f Electron microscopy showing a viral particle measuring $67.3 \mathrm{~nm}$ with electron-dense surface and the typical spikes in pneumocyte cytoplasm (a, c Alkaline phosphatase immunohistochemistry $\times 150, \times 100, \mathbf{b}, \mathbf{d}$, e Diaminobenzidine RNAish $\times 150$, $\times 100, \times 150, \mathbf{f}$ Transmission electron microscopy, $\times 100,000$ ).

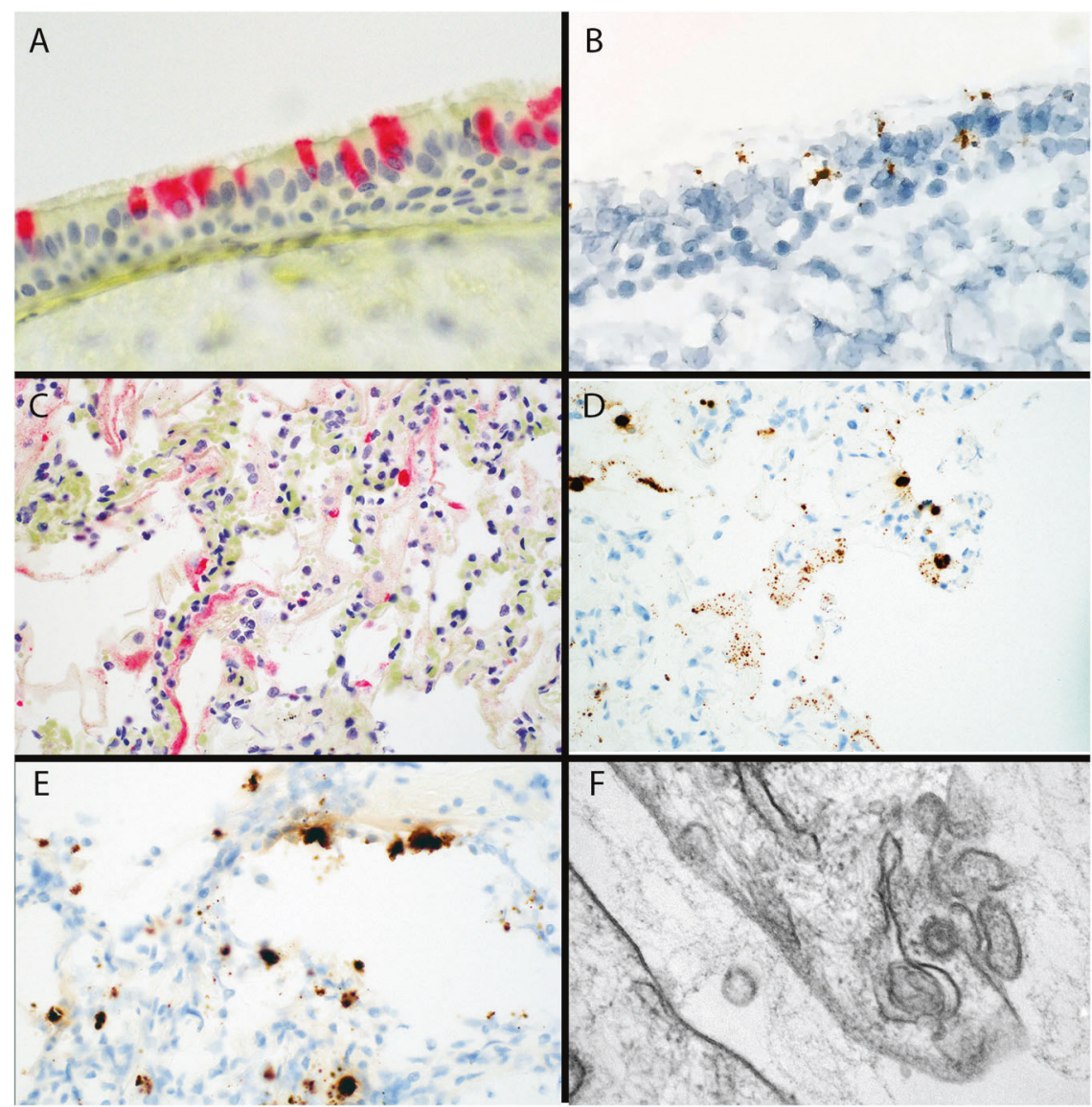

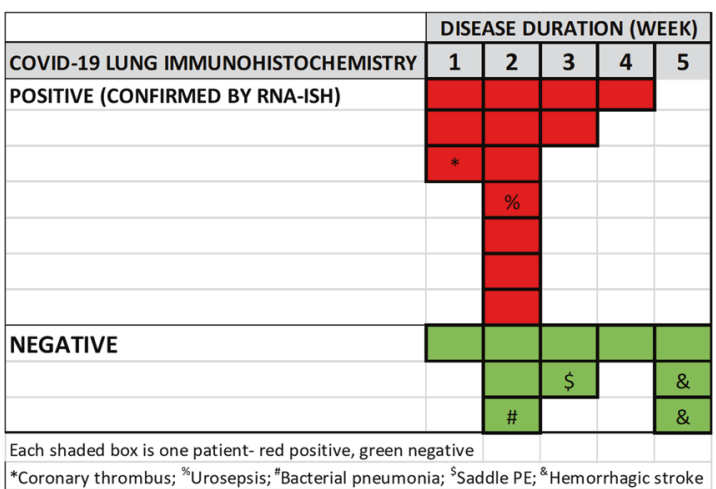

Fig. 8 COVID-19 in lung tissue by week of disease. Immunohistochemistry for viral spike protein, with positives confirmed by RNAish, tabulated by week of disease. Each box is one positive case with red positive, and green negative. The autopsy finding of associated immediate cause of death, if not solely from COVID-19 lung injury, is shown by symbols.

\section{COVID-19 pneumonia as a vascular and thrombotic disease}

In our extensive sampling, thrombi and vascular injury of both small- and mid-sized pulmonary vessels are a common alteration. Sometimes thrombi were not associated with areas of acute lung injury, distinct from SARS where they were described in areas of acute DAD. Many thrombi were platelet rich, confirmed by CD61 immunohistochemistry. While vascular thrombi, both fibrin and platelet types, are reported as a component of DAD and would be expected to some extent given the damage to the alveolar capillary barrier and subsequent activation of repair mechanisms and the coagulation cascade, it does appear that the frequency and severity of this finding is higher in COVID-19. In addition, several of our cases had platelet thrombi or thrombotic microangiopathy in other organs including heart, skeletal muscle, kidney, liver, central nervous system, and soft tissue (data not shown). Interestingly, the frequency of large thrombi and microthrombi at autopsy was not associated with reported anticoagulation therapy.

Whether due to direct viral infection of endothelial cells, hypercoagulable state, or related to systemic immune reaction with the subsequent activation of thrombotic pathways, the vasculature of the lung and other organs appear to be a key aspect of COVID-19 disease pathogenesis. It is not an unexpected finding, as ACE2 receptors are also expressed on endothelial cells and the presence of viral inclusion particles has already been recently demonstrated by EM [43] and supported here. Whether the mechanism for micro-thrombus 
formation is distinct from the mechanism of larger vessel thrombosis is unknown; it is possible that deep lower extremity venous thrombosis and deep peri-prostatic venous plexus thrombosis, as suggested by the Hamburg series [22], accounts for the larger vessel thrombosis. The importance of this observation is that the prevention of platelet microthrombi and larger vessel "coagulationbased" thrombi may require different therapeutic approaches.

A noteworthy finding concerns neutrophil granulocytes. While neutrophils may reflect superinfection and ventilator associated pneumonia, a subset of our cases had rapid progression to severe respiratory failure without evidence of superinfection and without mechanical ventilation. In these particular cases, neutrophils were seen in association with alveolar wall injury, necrosis, and microthrombi. Whether this represents a common early stage of alveolitis and endotheliitis in all cases, eventually obscured by diffuse acute lung injury, or a manifestation of only a subset of rapid progressors is unknown. However, the ability of neutrophils to release neutrophil extracellular traps to drive acute tracheobronchitis, ARDS, and thrombosis has been suggested [44], and blocking their formation may be an avenue to ameliorating the severity of COVID-19 in at least a subset of patients.

\section{Duality of epithelial and vascular injury-support from other COVID-19 series and prior global viral pandemics}

Histological examinations of lungs have been relatively limited in number, related to the strict and rigorous guidelines for autopsy and restrictions of lung surgery during the pandemic. The first paper reported severe pulmonary damage with features of acute lung injury [45]. Most findings, from single institution case series, have also described edema and proteinaceous exudates with AT2 hyperplasia [46], perivascular lymphocytic inflammation with possible inclusions in atypical AT2 cells [47], large airway mucus plugging with hyaline membranes and inflammation [17]. Interestingly, in a series of six cases of postmortem biopsies, a pattern of acute fibrinous and organizing pneumonia (AFOP) but not other acute lung injury, was reported [16]; this pattern was not seen in our series. A 21 case autopsy series showed capillary congestion, microthrombi (10 cases), superimposed bronchopneumonia, pulmonary embolism (4 cases), hemorrhage (3 cases), and vasculitis [1]. A thrombotic microangiopathy was also seen in three cases. This series reported an association with diabetes, hypertension, obesity, vascular disease, and was also male predominant in its involvement [48], similar to our series. A report of biopsy autopsies showed hyaline membranes, AT2 cell hyperplasia, and changes of DAD in addition to pneumocytes with amphophilic granular cytoplasm [49]. In report of 12 cases focusing on thromboembolic events, deep venous thrombosis was seen in $58 \%$ of patients with pulmonary embolus as the cause of death in four [19] and DAD in eight. These observations lend support to direct pulmonary epithelial injury as well as vascular/endothelial complications.

Some of the characteristics observed in our case series are shared by prior severe global pandemics, SARS, MERS, and H1N1 influenza. Thus, it is of interest to compare these entities. In severe cases of influenza, patterns of lung injury including DAD in exudative and/or organizing phase were identified [38, 39]. While descriptions of MERS are fewer in number, DAD, syncytial cells, and disease confined to the lungs was described [50]. The reports of SARS confirmed these features. Moreover, a temporality has been noted: in cases under 10 days, fibrin and hyaline membranes were demonstrated, and in later cases, type 2 cell hyperplasia, giant cells, and squamous metaplasia [51, 52]. In another series of 20 autopsies, together with DAD, AFOP was also encountered and squamous metaplasia in cases with a long duration of the disease [53].

Autopsy studies are limited in that serial sampling in the course of the disease cannot be performed, and the association of clinical parameters with outcome or efficacy of therapeutics cannot be determined. However, the underlying disease injury patterns of severe cases can be reported and put into context with prior viral pulmonary diseases, with the intent that the most severe of complications can be avoided in future patients.

Overall, our series of 68 autopsies from Italy and New York City show a consistent pattern of tracheobronchitis, alveolar injury, and vascular/thrombotic disease in patients with frequent co-morbidities such as hypertension and diabetes. As disease moves from the nasal passages to the upper respiratory tract and then to alveolar zones, acute alveolar injury is seen with viral associated, hyaline membrane lung injury; these foci persist well into week 2 of disease, and on occasion longer. One important manifestation is the high frequency of thrombi, especially platelet thrombi. Our findings highlight a high complexity of COVID-19 disease, involving several compartments, from upper airways (trachea, bronchi) to lung parenchyma, and the vascular bed. All these aspects could have an impact on clinical management. Thus, a deeper awareness and a better knowledge of histological alterations could lead to more appropriate diagnostic and therapeutic approaches.

Acknowledgements The Weill Cornell Pathology translational research laboratory provided technical support for the immunohistochemistry and in situ hybridization assays.

\section{Compliance with ethical standards}

Conflict of interest The authors declare that they have no conflict of interest. 
Publisher's note Springer Nature remains neutral with regard to jurisdictional claims in published maps and institutional affiliations.

\section{References}

1. Zhu N, Zhang D, Wang W, Li X, Yang B, Song J, et al. A novel coronavirus from patients with pneumonia in China, 2019. N Engl J Med. 2020;382:727-33.

2. Cucinotta D, Vanelli M. WHO declares COVID-19 a pandemic. Acta Biomed. 2020;91:157-60.

3. Huang C, Wang Y, Li X, Ren L, Zhao J, Hu Y, et al. Clinical features of patients infected with 2019 novel coronavirus in Wuhan, China. Lancet. 2020;395:497-506.

4. Zhang $\mathrm{H}$, Penninger JM, Li Y, Zhong N, Slutsky AS. Angiotensin-converting enzyme 2 (ACE2) as a SARS-CoV-2 receptor: molecular mechanisms and potential therapeutic target. Intensive Care Med. 2020;46:586-90.

5. Lukassen S, Chua RL, Trefzer T, Kahn NC, Schneider MA, Muley T, et al. SARS-CoV-2 receptor ACE2 and TMPRSS2 are primarily expressed in bronchial transient secretory cells. EMBO J. 2020;39:e105114.

6. Pei G, Zhang Z, Peng J, Liu L, Zhang C, Yu C, et al. Renal involvement and early prognosis in patients with COVID-19 pneumonia. J Am Soc Nephrol. 2020;31:1157-65.

7. Su H, Yang M, Wan C, Yi LX, Tang F, Zhu HY, et al. Renal histopathological analysis of 26 postmortem findings of patients with COVID-19 in China. Kidney Int. 2020;98:219-27.

8. Li Y, Xiao SY. Hepatic involvement in COVID-19 patients: pathology, pathogenesis, and clinical implications. J Med Virol. 2020;92:1491-4.

9. Asadi-Pooya AA, Simani L. Central nervous system manifestations of COVID-19: a systematic review. J Neurol Sci. 2020;413:116832-5.

10. Bikdeli B, Madhavan MV, Jimenez D, Chuich T, Dreyfus I, Driggin E, et al. COVID-19 and thrombotic or thromboembolic disease: implications for prevention, antithrombotic therapy, and follow-up. J Am Coll Cardiol. 2020;75:2950-73.

11. Englert JA, Bobba C, Baron RM. Integrating molecular pathogenesis and clinical translation in sepsis-induced acute respiratory distress syndrome. JCI Insight. 2019;4:1-13.

12. Bos LD, Paulus F, Vlaar APJ, Beenen LFM, Schultz MJ. Subphenotyping ARDS in COVID-19 patients: consequences for ventilator management. Ann Am Thorac Soc. 2020, online ahead of print.

13. Chung M, Bernheim A, Mei X, Zhang N, Huang M, Zeng X, et al. CT imaging features of 2019 novel coronavirus (2019-nCoV). Radiology. 2020;295:202-7.

14. Bernheim A, Mei X, Huang M, Yang Y, Fayad ZA, Zhang N, et al. Chest CT findings in coronavirus disease-19 (COVID-19): relationship to duration of infection. Radiology. 2020;295: 200463.

15. Barton LM, Duval EJ, Stroberg E, Ghosh S, Mukhopadhyay S. COVID-19 Autopsies, Oklahoma, USA. Am J Clin Pathol. 2020;153:725-33.

16. Copin MC, Parmentier E, Duburcq T, Poissy J, Mathieu D, Lille C-I, et al. Time to consider histologic pattern of lung injury to treat critically ill patients with COVID-19 infection. Intensive Care Med. 2020;46:1124-6.

17. Konopka KE, Wilson A, Myers JL. Postmortem lung findings in an asthmatic patient with coronavirus disease 2019. Chest. 2020; S0012-3692:30775-3.

18. Tian S, Xiong Y, Liu H, Niu L, Guo J, Liao M, et al. Pathological study of the 2019 novel coronavirus disease (COVID-19) through postmortem core biopsies. Mod Pathol. 2020;33:1007-14.
19. Wichmann D, Sperhake JP, Lutgehetmann M, Steurer S, Edler C, Heinemann A, et al. Autopsy findings and venous thromboembolism in patients with COVID-19. Ann Intern Med. 2020; 173:268-77.

20. Bosmuller H, Traxler S, Bitzer M, Haberle H, Raiser W, Nann D, et al. The evolution of pulmonary pathology in fatal COVID-19 disease: an autopsy study with clinical correlation. Virchows Arch. 2020;477:349-57.

21. Carsana L, Sonzogni A, Nasr A, Rossi RS, Pellegrinelli A, Zerbi $\mathrm{P}$, et al. Pulmonary post-mortem findings in a series of COVID-19 cases from northern Italy: a two-centre descriptive study. Lancet Infect Dis. 2020;S1473-3099:30434-5.

22. Edler C, Schroder AS, Aepfelbacher M, Fitzek A, Heinemann A, Heinrich F, et al. Dying with SARS-CoV-2 infection-an autopsy study of the first consecutive 80 cases in Hamburg, Germany. Int J Leg Med. 2020;134:1275-84.

23. Fox SE, Akmatbekov A, Harbert JL, Li G, Quincy Brown J, Vander Heide RS. Pulmonary and cardiac pathology in African American patients with COVID-19: an autopsy series from New Orleans. Lancet Respir Med. 2020;8:681-6.

24. Martines RB, Ritter JM, Matkovic E, Gary J, Bollweg BC, Bullock $\mathrm{H}$, et al. Pathology and pathogenesis of SARS-CoV-2 associated with fatal coronavirus disease, United States. Emerg Infect Dis. 2020;26:2005-15.

25. Nunes Duarte-Neto A, de Almeida Monteiro RA, da Silva LFF, Malheiros D, de Oliveira EP, Theodoro Filho J, et al. Pulmonary and systemic involvement of COVID-19 assessed by ultrasoundguided minimally invasive autopsy. Histopathology. 2020, online ahead of print.

26. Wu JH, Li X, Huang B, Su H, Li Y, Luo DJ, et al. Pathological changes of fatal coronavirus disease 2019 (COVID-19) in the lungs: report of 10 cases by postmortem needle autopsy. Zhonghua Bing Li Xue Za Zhi. 2020;49:568-75.

27. Lavezzo E, Franchin E, Ciavarella C, Cuomo-Dannenburg G, Barzon L, Del Vecchio C, et al. Suppression of a SARS-CoV-2 outbreak in the Italian municipality of Vo'. Nature. 2020;584 :425-9.

28. Whimster WF, Macfarlane AJ. Normal lung weights in a white population. Am Rev Respir Dis. 1974;110:478-83.

29. Guan WJ, Ni ZY, Hu Y, Liang WH, Ou CQ, He JX, et al. Clinical characteristics of coronavirus disease 2019 in China. N Engl J Med. 2020;382:1708-20.

30. Lippi G, Henry BM. Active smoking is not associated with severity of coronavirus disease 2019 (COVID-19). Eur J Intern Med. 2020;75:107-8.

31. Zhao Q, Meng M, Kumar R, Wu Y, Huang J, Lian N, et al. The impact of COPD and smoking history on the severity of COVID19: a systemic review and meta-analysis. J Med Virol. 2020; https://doi.org/10.1002/jmv.25889.

32. Brake SJ, Barnsley K, Lu W, McAlinden KD, Eapen MS, Sohal SS. Smoking upregulates angiotensin-converting enzyme-2 receptor: a potential adhesion site for novel coronavirus SARSCoV-2 (COVID-19). J Clin Med. 2020;9:841.

33. Leung JM, Yang CX, Tam A, Shaipanich T, Hackett TL, Singhera GK, et al. ACE-2 expression in the small airway epithelia of smokers and COPD patients: implications for COVID-19. Eur Respir J. 2020;55:2000688. https://doi.org/10.1183/13993003. 00688-2020. Published 14 May 2020.

34. Xia T, Li J, Gao J, Xu X. Small solitary ground-glass nodule on $\mathrm{CT}$ as an initial manifestation of coronavirus disease 2019 (COVID-19) Pneumonia. Korean J Radiol. 2020;21:545-9.

35. Shi H, Han X, Jiang N, Cao Y, Alwalid O, Gu J, et al. Radiological findings from 81 patients with COVID-19 pneumonia in Wuhan, China: a descriptive study. Lancet Infect Dis. 2020;20:425-34 
36. Yuan M, Yin W, Tao Z, Tan W, Hu Y. Association of radiologic findings with mortality of patients infected with 2019 novel coronavirus in Wuhan, China. PLoS ONE. 2020;15:e0230548.

37. Verger A, Bahloul A, Melki S, Karcher G, Imbert L, Marie PY. Tracheobronchitis signs observed on ventilation lung scintigraphy during the course of COVID-19 infection. Eur J Nucl Med Mol Imaging. 2020;6:1-2.

38. Gill JR, Sheng ZM, Ely SF, Guinee DG, Beasley MB, Suh J, et al. Pulmonary pathologic findings of fatal 2009 pandemic influenza A/H1N1 viral infections. Arch Pathol Lab Med. 2010;134: $235-43$.

39. Nakajima N, Sato Y, Katano H, Hasegawa H, Kumasaka T, Hata $\mathrm{S}$, et al. Histopathological and immunohistochemical findings of 20 autopsy cases with 2009 H1N1 virus infection. Mod Pathol. 2012;25:1-13.

40. Sauter JL, Baine MK, Butnor KJ, Buonocore DJ, Chang JC, Jungbluth AA, et al. Insights into pathogenesis of fatal COVID-19 pneumonia from histopathology with immunohistochemical and viral RNA studies. Histopathology. 2020, published online ahead of print.

41. Schaefer IM, Padera RF, Solomon IH, Kanjilal S, Hammer MM, Hornick JL, et al. In situ detection of SARS-CoV-2 in lungs and airways of patients with COVID-19. Mod Pathol. 2020; 1-11. https://doi.org/10.1038/s41379-020-0595-z.

42. Sungnak W, Huang N, Becavin C, Berg M, Queen R, Litvinukova $\mathrm{M}$, et al. SARS-CoV-2 entry factors are highly expressed in nasal epithelial cells together with innate immune genes. Nat Med. 2020;26:681-7.

43. Ackermann M, Verleden SE, Kuehnel M, Haverich A, Welte T, Laenger F, et al. Pulmonary vascular endothelialitis, thrombosis, and angiogenesis in COVID-19. N Engl J Med. 2020;9:120-8.

44. Barnes BJ, Adrover JM, Baxter-Stoltzfus A, Borczuk A, CoolsLartigue J, Crawford JM, et al. Targeting potential drivers of COVID-19: neutrophil extracellular traps. J Exp Med. 2020;217: e20200652.
45. Yao XH, He ZC, Li TY, Zhang HR, Wang Y, Mou H, et al. Pathological evidence for residual SARS-CoV-2 in pulmonary tissues of a ready-for-discharge patient. Cell Res. 2020;30:541-3.

46. Tian $\mathrm{S}, \mathrm{Hu}$ W, Niu L, Liu H, Xu H, Xiao SY. Pulmonary pathology of early-phase 2019 novel coronavirus (COVID-19) pneumonia in two patients with lung cancer. J Thorac Oncol. 2020;15:700-4.

47. Zeng Z, Xu L, Xie XY, Yan HL, Xie BJ, Xu WZ, et al. Pulmonary pathology of early phase COVID-19 pneumonia in a patient with a benign lung lesion. Histopathology. 2020. https://doi.org/10.1111/ his. 14138.

48. Menter T, Haslbauer JD, Nienhold R, Savic S, Hopfer H, Deigendesch N, et al. Post-mortem examination of COVID19 patients reveals diffuse alveolar damage with severe capillary congestion and variegated findings of lungs and other organs suggesting vascular dysfunction. Histopathology. 2020. https://doi.org/10. 1111/his.14134.

49. Xu Z, Shi L, Wang Y, Zhang J, Huang L, Zhang C, et al. Pathological findings of COVID-19 associated with acute respiratory distress syndrome. Lancet Respir Med. 2020;8:420-2.

50. Ng DL, Al Hosani F, Keating MK, Gerber SI, Jones TL, Metcalfe MG, et al. Clinicopathologic, immunohistochemical, and ultrastructural findings of a fatal case of middle east respiratory syndrome coronavirus infection in the United Arab Emirates, April 2014. Am J Pathol. 2016;186:652-8.

51. Franks TJ, Chong PY, Chui P, Galvin JR, Lourens RM, Reid AH, et al. Lung pathology of severe acute respiratory syndrome (SARS): a study of 8 autopsy cases from Singapore. Hum Pathol. 2003;34:743-8.

52. Ksiazek TG, Erdman D, Goldsmith CS, Zaki SR, Peret T, Emery $\mathrm{S}$, et al. A novel coronavirus associated with severe acute respiratory syndrome. N Engl J Med. 2003;348:1953-66.

53. Hwang DM, Chamberlain DW, Poutanen SM, Low DE, Asa SL, Butany J. Pulmonary pathology of severe acute respiratory syndrome in Toronto. Mod Pathol. 2005;18:1-10. 